\title{
Infodemiological study on COVID-19 epidemic and COVID-19 infodemic
}

\author{
Zhiwen $\mathrm{Hu}^{\mathrm{a}}$, Zhongliang Yang ${ }^{\mathrm{b}}$, Qi Li ${ }^{\mathrm{b}}$, An Zhang ${ }^{\mathrm{c}}$, Yongfeng Huang ${ }^{\mathrm{b}, *}$ \\ ${ }^{a}$ School of Computer and Information Engineering, Zhejiang Gongshang University, Hangzhou 310018, China \\ ${ }^{b}$ Beijing National Research Center for Information Science and Technology (BNRist), Tsinghua University, Beijing 100084, China \\ ${ }^{c}$ State Key Laboratory of Resources and Environmental Information System, Institute of Geographical Sciences and Natural Resources Research, Chinese \\ Academy of Sciences, Beijing 100101, China
}

\begin{abstract}
Less aligned emphasis has been given to the COVID-19 infodemic coordinating with the COVID-19 outbreak. Global profusion of tangled monikers and hashtags has found their ways in daily communication and contributed to backlash against Chinese. Official naming efforts against infodemic should be meet with a fair share of identification. Based on brief critical reviews on previous multifarious naming practices, we punctuate heuristic introspection in scientific conventions and sociocultural paradigms. Infodemiological analysis promises to articulate that people around the globe are divided in their favor stigmatized monikers in the public and scientific communities because of perceptual bias. There is no positive correlation between the degree of infection in their territories and collective perceptual bias to COVID-19. The official portfolio "COVID-19" and "SARS-CoV-2" has not become de facto standard usages, but full-fledged official names are excepted to duly contribute to the resilience of negative perceptual bias and collective behavioral propensities.
\end{abstract}

Keywords: Infodemiology; COVID-19 infodemic; social contagion; collective perceptual bias; collective behavioral propensities; psychological typhoon eye effect

* Corresponding author. E-mail address: yfhuang@tsinghua.edu.cn (Yongfeng Huang) 


\section{Introduction}

On the occasion of the Chinese Lunar New Year of 2020, the 2019 novel coronavirus disease (now known as COVID-19 ${ }^{1}$ ) was first reported from Wuhan City of China, home to 11 million people. With the spread of the COVID-19 epidemic, massive infodemic has undermined and disrupted global efforts to fight epidemic. However, hitherto the infodemic rarely appears in publications to meet with a fair share of identification, and even its unique risk has only been flirted with. For the underrepresented minority case in academia ${ }^{2,3}$, the "2019-nCoV infodemic" (hereinafter, COVID-19 infodemic) is duly credited with the remarks "the high demand for timely and trustworthy information about 2019-nCoV".

On one hand, global profusion of running headlines often inscribe fear, prejudice, disgust and hostility into tangled hashtags and monikers, branding ethnic accusations intentionally misleading. Those monikers and morbid contents always team up with each other in the epicenter of infodemic, wherein one sheds light on the social contagion of the other. The past few weeks has witnessed an explosive growth of stigmatized monikers, which have found their ways in daily communication and contributed to backlash against Chinese and diaspora.

On the other hand, no learned name, no fighting flag of information confrontation with disinformation campaign. There is looming concern that appropriate nomenclatures should be duly assigned to the newly identified coronavirus and caused respiratory tract disease in humans, which has potential public health impact. So far, there are not universally accepted names yet, either for academic-industrial usage or consistency with international virus taxonomy.

To address such pressing issues, we orchestrate rich metadata available to unfold the picture of the COVID-19 epidemic and COVID19 infodemic in this infodemiological study.

\section{Results}

\section{Unfolding history: coronavirus and human coronaviruses}

Before gauging COVID-19 epidemic and COVID-19 infodemic, it is necessary to take a glimpse into the history of scientific taxonomy and nomenclature of emerging virus and infectious disease ${ }^{4}$. In 1966, an International Committee on Nomenclature of Viruses (ICNV) was established with the mission of introducing some degree of order and consistency into the naming of viruses. In 1973, the ICNV became the International Committee on Virus Taxonomy (ICTV), a global authority on the designation and naming of viruses. Another international authoritative body, WHO is responsible for naming new human infectious diseases.

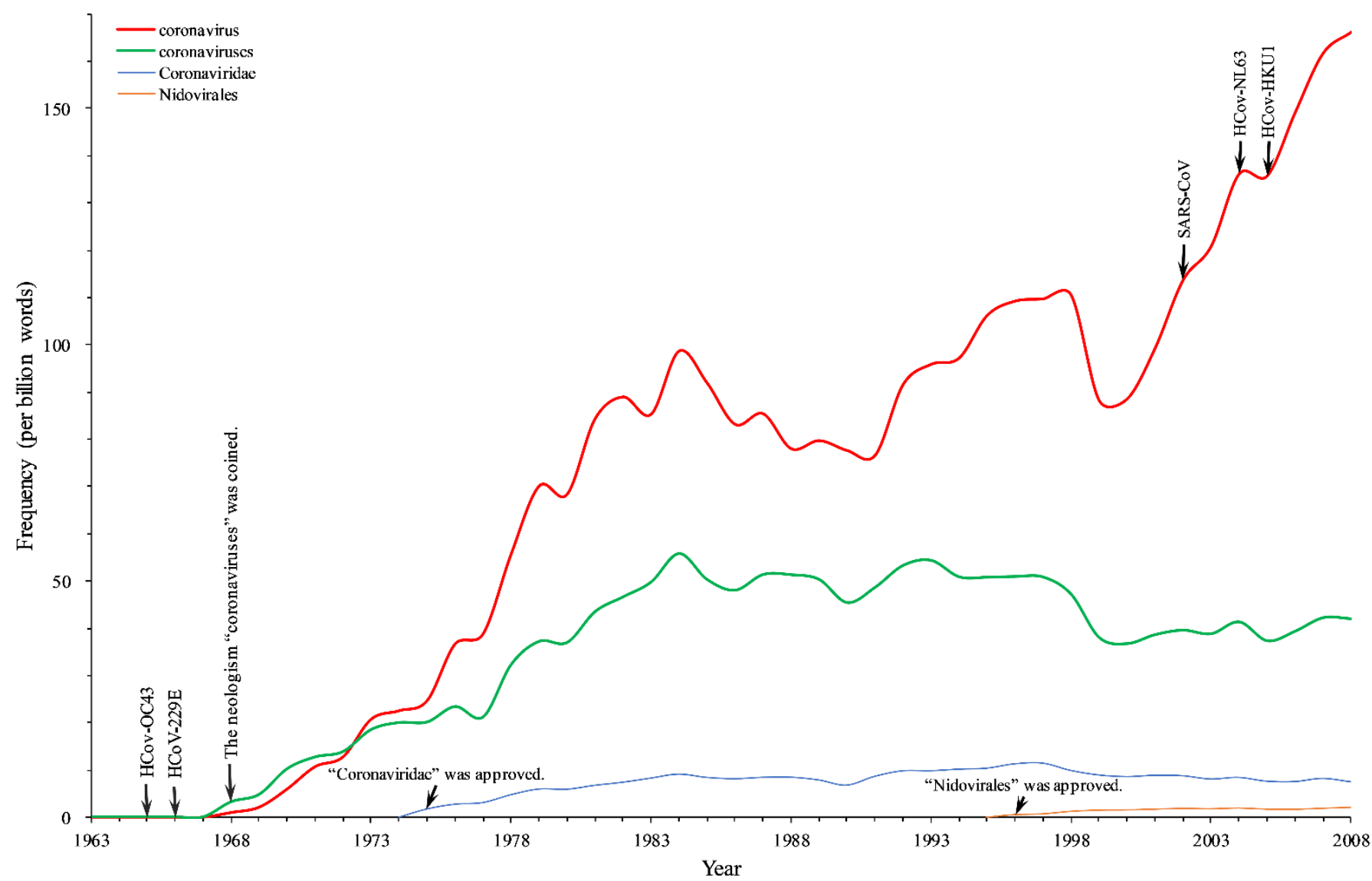

Figure 1. Diachronic discourse of "coronavirus", "coronaviruses", "Coronaviridae" and "Nidovirales" in English corpus from 1963 to 2008. GBNC facsimiles the word frequency of "coronavirus", "coronaviruses", "Coronaviridae" and "Nidovirales" in English corpus from 1963 to 2008 , respectively. After the initial description of coronaviruses in $1968^{5}$, there was a mild increase in the numbers of printed books dealing with them, followed by several peaks, after several human coronavirus epidemics: SARS-CoV in 2002-2003, HCoV-NL63 in 2004 and HCoV-HKU1 in 2005. In 1971, "coronaviruses" was officially approved by ICNV ${ }^{6,7}$. The terms "Coronaviridae", "Nidovirales" and "Coronavirinae" were officially approved by ICTV in $1975,1996,2009$, respectively. 
However, as an earlier nomenclature practice, the naming history of coronaviruses $(\mathrm{CoV})$ is always misjudged in scientific community (Figure 1). In retrospect, on 16 November 1968, eight distinguished virologists proposed the term "coronaviruses" in a brief annotation of Nature ${ }^{5}$. In fact, unsung virologist Anthony Peter Waterson (1923 - 1983) and his colleagues should be credited with the coinage of the neologism "coronavirus" 8,9 [Personal communication with Prof. Kenneth McIntosh, the only survivor of the authors of the annotation in Nature that proposed this name $e^{5}$. In humans, there are 7 spectrums of human coronaviruses (HCoVs) known to cause the common cold as well as more severe respiratory disease. Of those, human coronaviruses HCoV-229E, HCoV-NL63, HCoV-OC43 and HCoVHKU1 are routinely responsible for mild respiratory illnesses like the common cold but can cause severe infections in immunocompromised individuals. But three members have caused deadly outbreaks: SARS-CoV, MERS-CoV, and the newly identified coronaviruses (now known as SARS-CoV-2 ${ }^{10}$ ).

The diachronic discourse of "coronavirus" and "coronaviruses" in English corpus from 1960 to 2008 unveils that there was a mild increase in the numbers of printed books dealing with HCoVs after the initial description of coronaviruses in 1968. Then, each human coronavirus epidemic - SARS-CoV in 2002-2003, HCoV-NL63 in 2004 and HCoV-HKU1 in 2005 - leads to a new wave of hot research (Figure 1).

Furtherly, meta-analysis results of WoS and PubMed indicate that known knowledge still remains off-limit in the field of combating emerging HCoVs (Figure 2). SARS-CoV-2 is the seventh identified coronavirus that can cause diseases of the respiratory tract via humanto-human transmission. It caused mysterious pneumonia outbreak is spreading far more quickly than the SARS-CoV and MERS-CoV diseases $^{1,11,12}$, although the epicenter of the outbreak was locked down to curb the pandemic spread ${ }^{13}$. Presently, its clinical severity is yet to be determined, although many fatal cases have occurred. In sum, the enigmatic nature of HCoVs and the many unknowns about the pandemics have put people on edge.

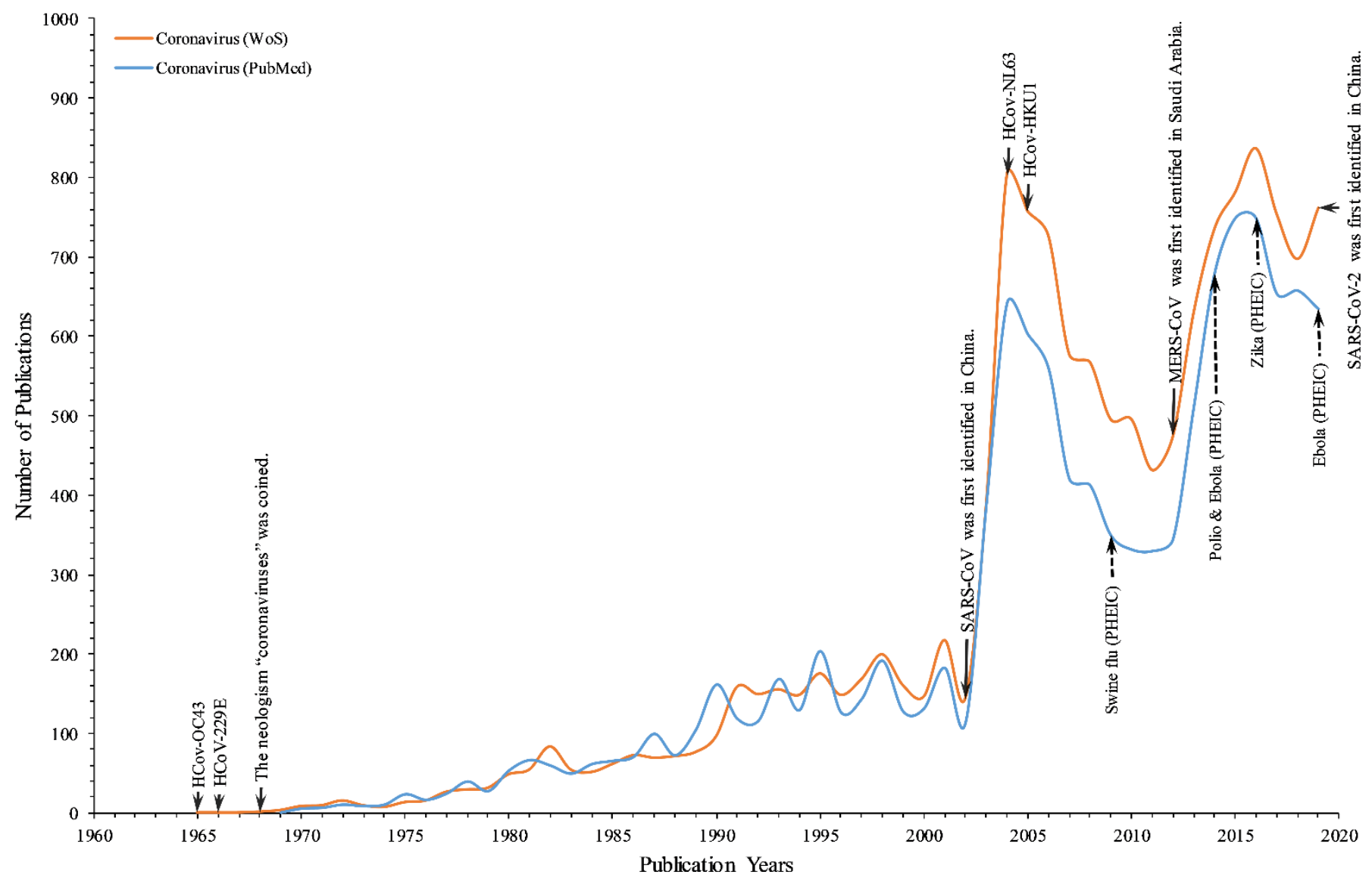

Figure 2. Number of publications with "coronavirus" in Web of Science and PubMed. Coronaviruses are positive-sense single-stranded RNA viruses found in a wide variety of animals, as well as in humans. Seven strains of respiratory coronaviruses known to infect human-to-human: HCoV-OC43 (1965), HCoV-229E (1966), SARS-CoV (2002), HCoV-NL63 (2004), HCoV-HKU1 (2005), MERS-CoV (2012) and SARS-CoV-2 (2019). WHO declared the 2019-nCoV outbreak a public health emergency of international concern (PHEIC) on 30 January 2020. This is the 6th time WHO has declared a PHEIC since the International Health Regulations (IHR) came into force in 2005. Before that, there have been five global health emergencies since such declaration was formalized: swine flu (2009), polio (2014), Ebola (2014 then again in 2019), and Zika (2016).

\section{Does a virus' name really matter?}

In fact, an 'inappropriate' official nomenclature might fuel infodemic unconsciously. In recent years, humans have witnessed several outbreaks of infectious diseases caused by viruses, with common names given by stakeholders. Each round of naming practice is not always successful. As a case in point, some strongly-held but flawed names such as "Middle Eastern Respiratory Syndrome"14 and "Swine flu" were accused of unintentional social impacts and negative economic by stigmatizing certain industries or communities (Figure 2). "Swine flu," an influenza strain known to have originated in pigs, resulted in causing great financial damage to farmers, despite there being no evidence that it could be spread via pork consumption. Since these incidents, in May 2015, WHO released some naming conventions for the naming of new human diseases ${ }^{15}$. 
Unfortunately, with the spread of COVID-19 epidemic, another massive infodemic spread virally over the world with recurring drama. Previous evidence suggests that the Internet, by its very nature, could amplify and relay such infodemic swiftly worldwide, cause exaggerated panic and worsen stigmatization against people in the epicenter of outbreak progressively ${ }^{16-18}$. Much worse in the current infodemic, Corona beer is being slashed by the name's similarity to the deadly coronavirus. In fact, the Mexican brand originated back in 1925 before the first strain of coronavirus was discovered and named, and nothing to do with coronavirus or virus. To address such challenge, WHO declared this infodemic as the "2019-nCoV infodemic" on 2 February 2.

Can we learn from history? To find the answer, we examine the popularity of top queries of current coronavirus epidemic via the Google Trends Index (Figure 3). Those dynamic shares are faithful indicators of collective behaviours across various regions over time. Currently, people around the globe are divided in their own options on the Internet and in daily communications. Comparatively, a striking feature was that some stigmatized monikers enjoy high frequencies of collective consumption. This finding reveal that the 2019 novel coronavirus is thought to have originated in China, which led to it being frequently named "Chinese coronavirus", "China coronavirus" or "Wuhan coronavirus". Our survey also pinpoint that those stigmatized names might have contributed to recent backlash against Chinese people. Notably, substantial pattern shifts are observed after the announcements of "2019-nCoV" and "COVID-19", whereas "SARSCoV-2" had failed to keep abreast of "COVID-19". The official portfolio "COVID-19" and "SARS-CoV-2" has not become de facto standard usages. But the portfolio of full-fledged official names would be beneficial to overdue correctives to current stigmatization in long run.

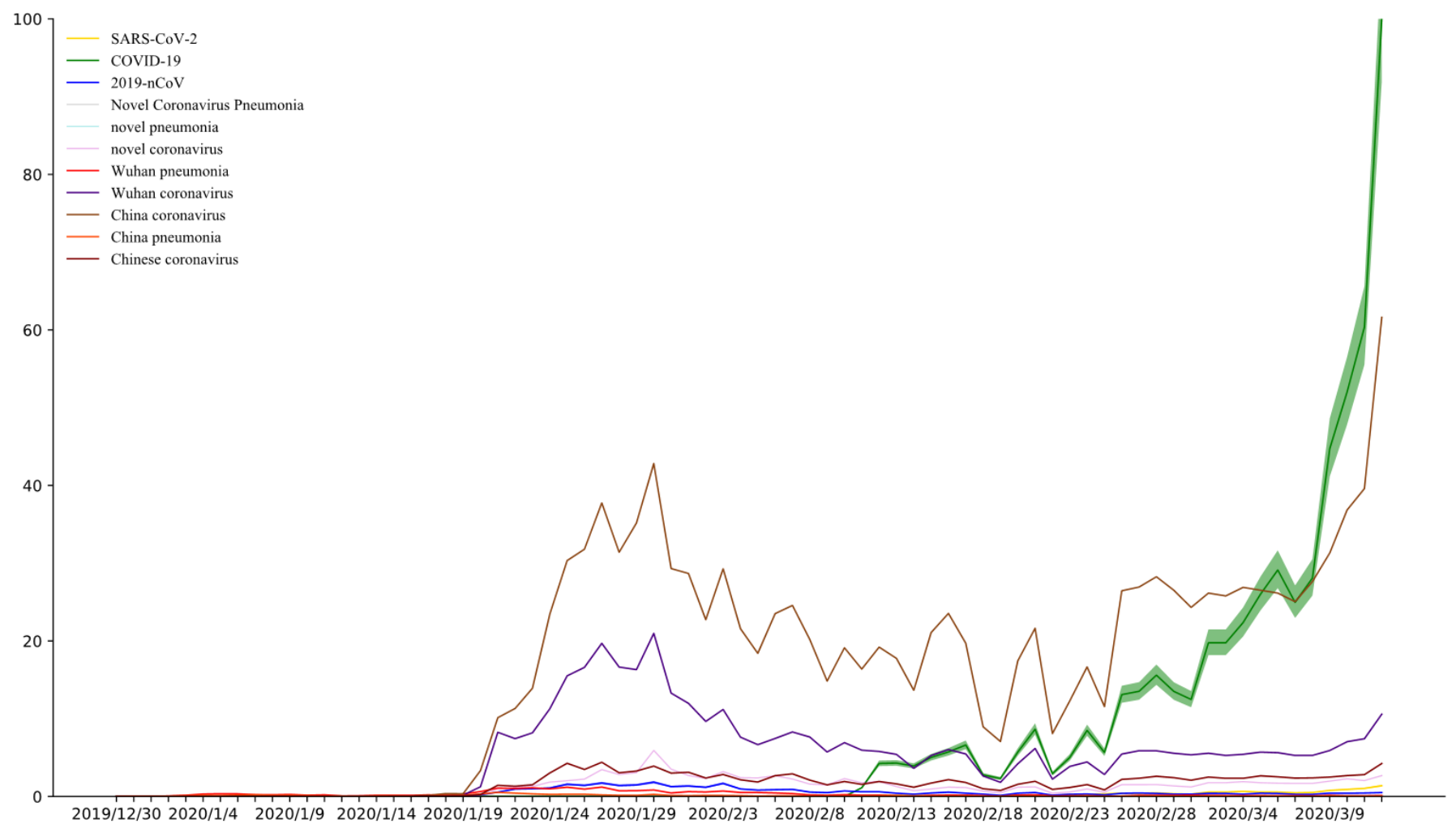

Figure 3. Illustration on the top query volumes of the 2019 novel coronavirus in infodemic scenario. The Google Trends facsimiles the popularity of "SARS-CoV-2" (gold), "COVID-19" (green), "2019-nCoV" (blue), "Novel Coronavirus Pneumonia" (grey), "novel pneumonia" (cyan), "novel coronavirus" (magenta), "Wuhan pneumonia" (red), "Wuhan coronavirus" (indigo), "China coronavirus" (brown), "China pneumonia" (orange) and "Chinese coronavirus" (maroon) from 30 January 2019 to 12 March 2020, respectively. After 16 January, multifarious stigmatized monikers against ethnic Chinese have prevailed in the public. "COVID-19" sets to take over the rally stick from "2019-nCoV", helping "2019-nCoV" complete its historic mission and surpassing "China coronavirus" on March 7.

\section{Collective perceptual bias to COVID-19 in the public}

To further examine the demographical perceptions of collective behavioral propensities in current infodemic, we characterize the relationship between geographical interest of stigmatized monikers and the cumulative rate of 58 countries and territories, in which confirmed cases of COVID-19 acute respiratory disease has been reported. The results clearly unveil that people in Egypt, Greece, New Zealand, United Kingdom, United States, Canada, Finland, Russia, Philippines, Denmark, Vietnam, Nepal and Mexico would prefer to use stigmatized monikers against Chinese, in comparison with other counterparts (Figure 4).

To characterize the patterns behind such collective perceptual bias, we further scrutinize geographical interest of stigmatized monikers against Chinese in 13 typical territories with low cumulative rates over time (Figure 5). As co-occurrence perceptual phenomena, the substantial illustration could corroborate that people have enjoyed stigmatized monikers with very high frequencies in these typical territories after 16 January 2020. People has negative perceptual bias in the perception of natural origin of COVID-19 in these regions. Moreover, people hold negative perception of the authoritative responses in many countries ${ }^{4,19-21}$. The prognostic significance of our findings is that such approaches are excepted to determine psychological typhoon eye effect - a paradoxical phenomenon that the respondents in the closer to the epicenter of pandemic appear to be the least concerned by the imminent risks - in the near future. 


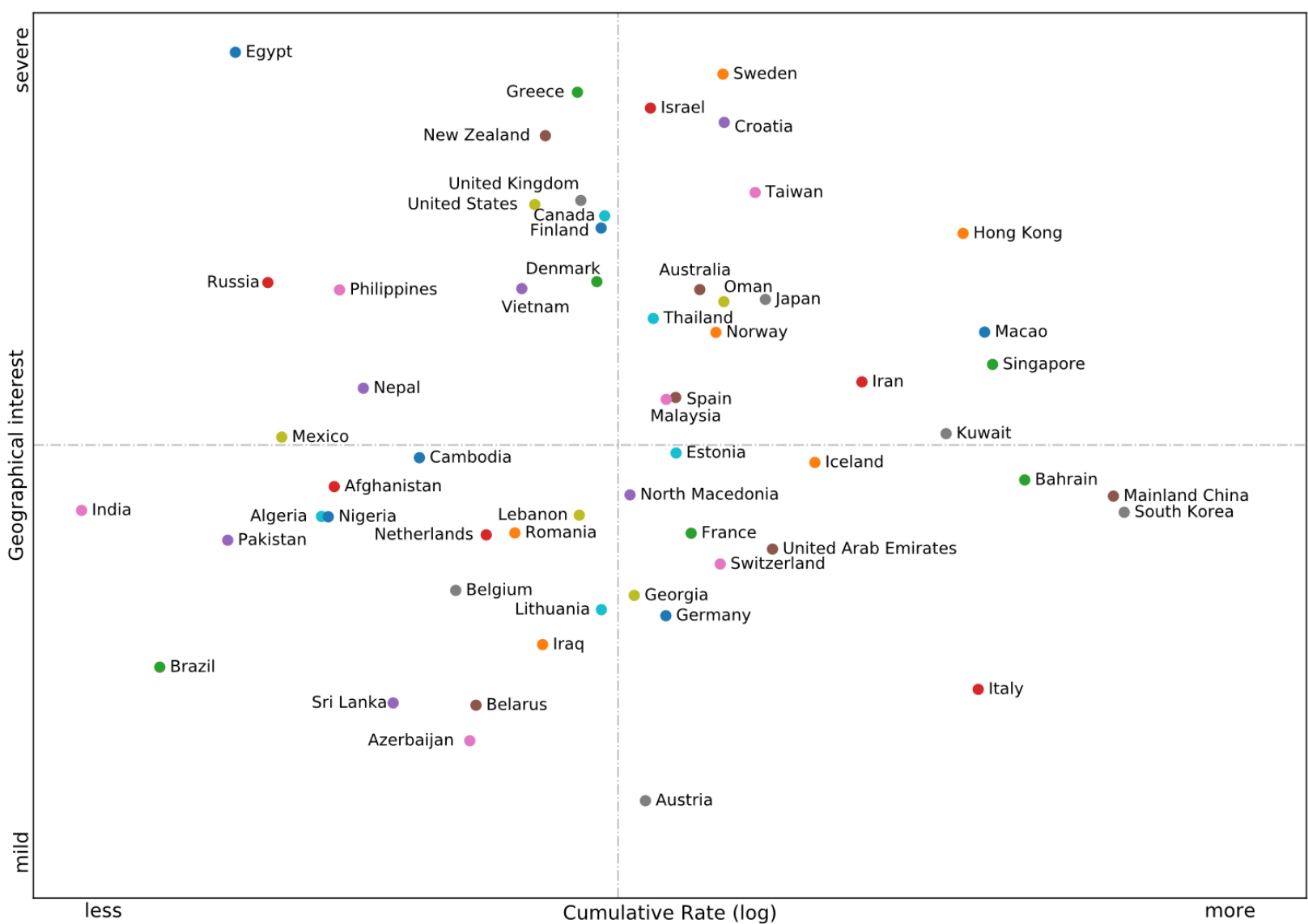

Figure 4. Four-quadrant diagram of the relationship between geographical interest of stigmatized monikers and cumulative rate. As of 29 February 2020, up to 60 countries and territories has reported confirmed cases of COVID-19 acute respiratory disease, including Taiwan, Iceland, Azerbaijan and Monaco. There are no metadata available for San Marino and Monaco in Google Trends, and geographical interest of stigmatized monikers against Chinese in other 58 territories was normalized by median volume for comparing each other. The cumulative rate is the ratio of the number of confirmed cases to the total populations in the countries or territories.

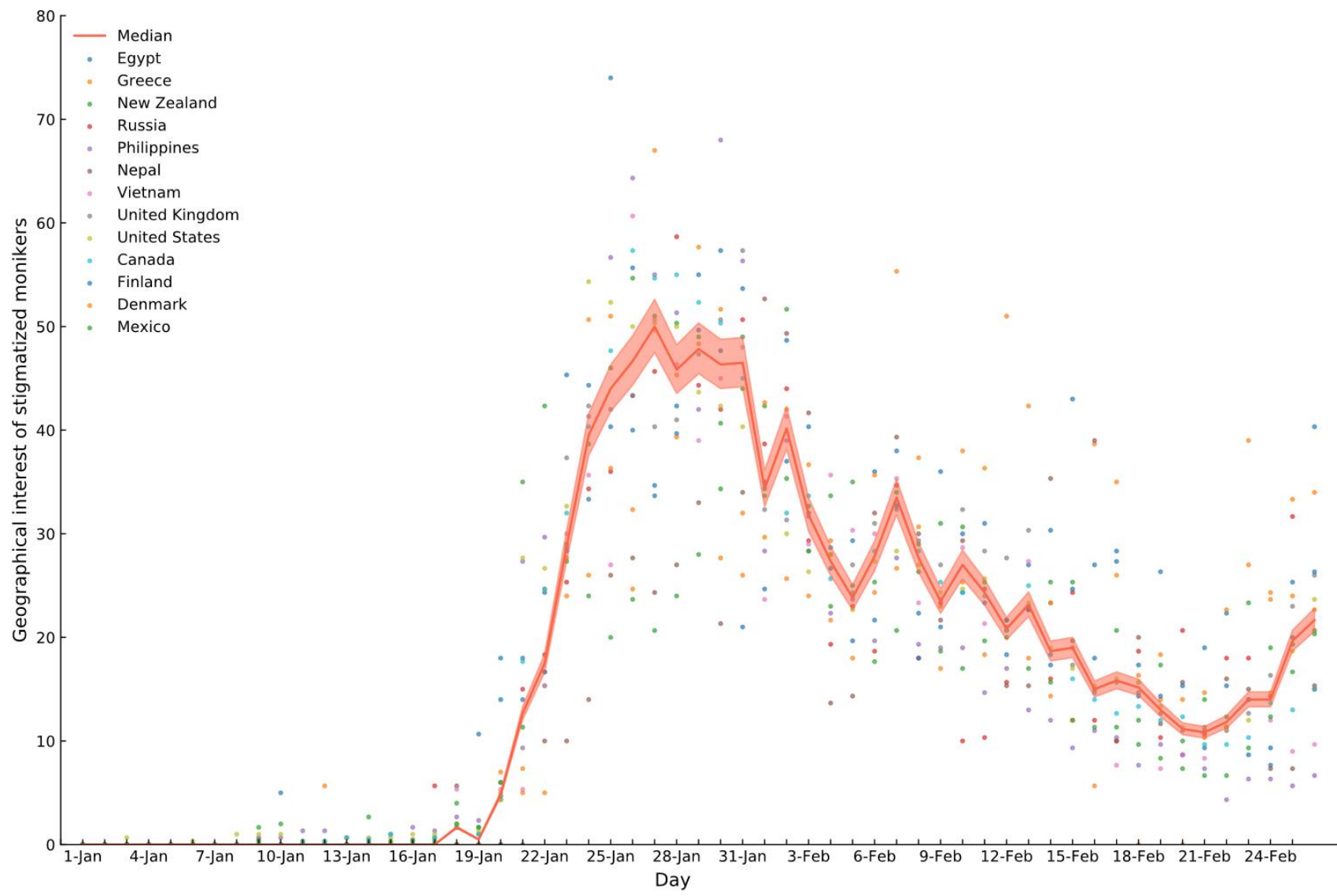


Figure 5. Dynamic interest of stigmatized monikers against Chinese in typical territories with low cumulative rates. This illustration unveils the geographical interest of stigmatized monikers in 13 typical territories - Egypt, Greece, New Zealand, United Kingdom, United States, Canada, Finland, Russia, Philippines, Denmark, Vietnam, Nepal and Mexico - between 1 January 2020 and 26 February 2020. The median volumes of the corresponding search queries facsimile the trend of collective behavioral propensities over time. Comparatively, some stigmatized monikers against Chinese have been enjoyed with very high frequencies after 16 January. The substantial pattern of high consistent curve indicates that negative perceptual bias is observed in the perception of natural origin of COVID-19 in the public.

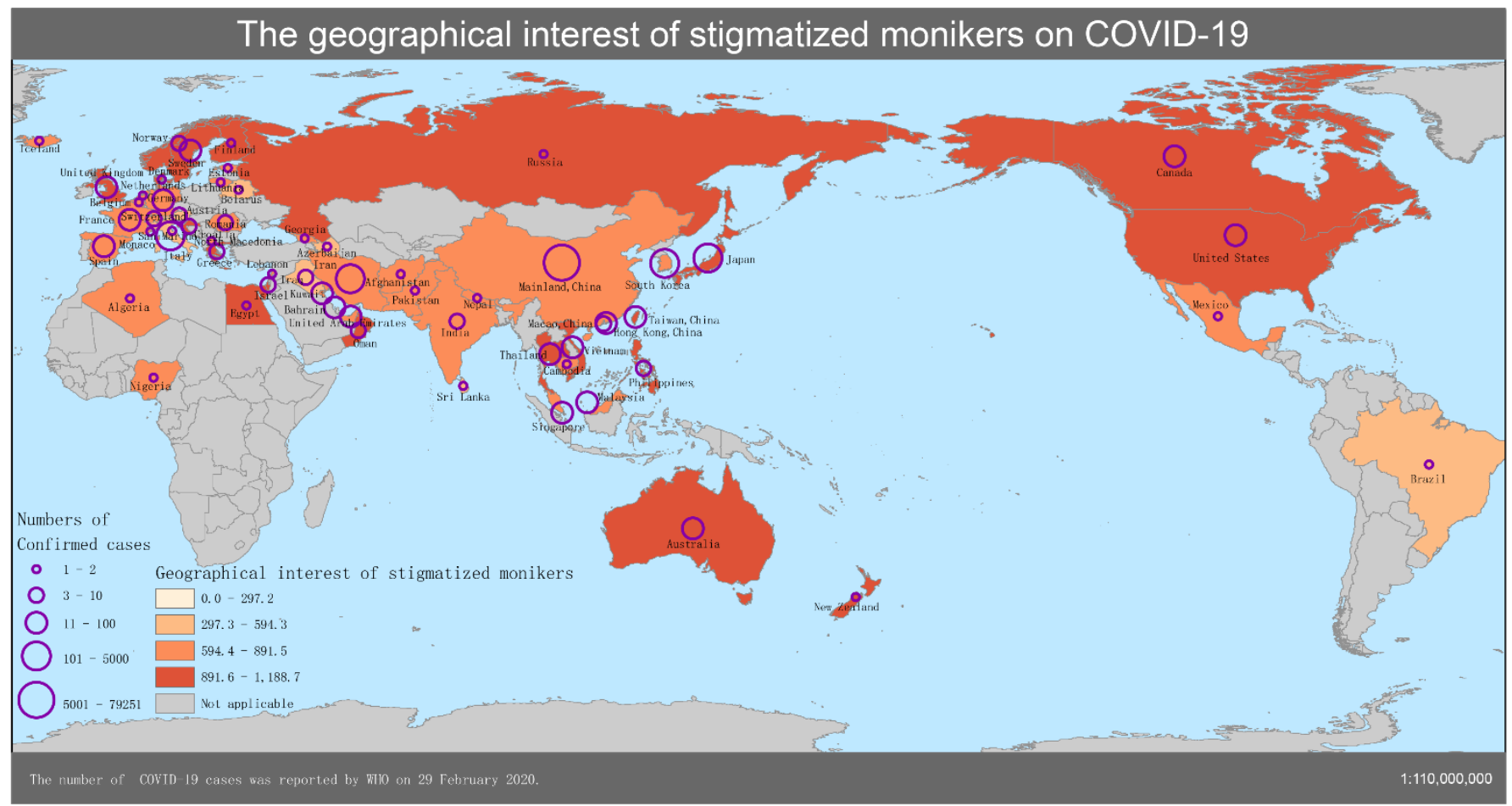

Figure 6. Geographical map of the COVID-19 infodemic (29 February 2020). Clearly, substantial pattern is also observed in the geographical map of 58 countries and territories with low cumulative rates and negative perceptual bias in the perception of natural origin of COVID-19 in the public.

People hold negative perceptual bias in the perception of natural origin of COVID-19 in the 58 countries and territories with low cumulative rates (Figure 6). In sociocultural setting with relatively complex dimensions beyond geographical structure, this approach of panoramic map empowers us to better understand the prevalence and severity of the COVID-19 infodemic throughout the regions comparatively. This finding reminds us that policy-makers should learn from best practice in the reduction of deliberate infodemic risks, with the pull of go-to resources for knowledge and expertise into academic sphere, as well as in the public.

What's the plausible reasons behind such collective perceptual bias? Demographically, according to Pew Research Center's latest Global Attitudes survey ${ }^{22}$, a median of $40 \%$ in the surveyed countries have a have a positive view of China, compared with a median of $41 \%$ who have an unfavorable opinion. However, recognizing COVID-19 acute respiratory disease with potential public health impact, people are easily impressed emotionally by distorted news from the media and neighbor individuals. When the emerging cases reported in their country, the infodemic about the cause of the epidemic flew to and fro and nothing seemed certain or obviously right. As a case in point, the Bill \& Melinda Gates Foundation, an American private foundation has spent billions on global healthcare, have been suspiciously accused of manufacturing this biowarfare to "wage economic war on China", jointly with the CIA. Such disinformation campaign reminds us that the army of authoritative organizations should work together with each other and cultivate a well-trained cadre of professionals to mediate infodemic risks.

Notably, from the very beginning of COVID-19 epidemic, people in most Asia-Pacific countries, "where many more name China as a top threat"22, prioritize relations with China to jointly fight the COVID epidemic, rather than malicious discrimination against Chinese. Regrettably, the underrepresented minority cases, some individuals and media have been committed for slashing China image to the bone by promoting unfounded conspiracy theories, such as non-natural origin of COVID-1923, made-in-China coronavirus (even desecration of Chinese national flag), "China is the real Sick Man of Asia", China's Chernobyl moment, etc. Some instigators have realized their mistakes and made an open apology to China, but some are intent on whitewashing their words and acts under the guise of freedom of speech.

Such ridiculous voices do nothing but breed the pathogen of fear, prejudice, disgust, and xenophobia. Undoubtedly, they have been levied harsh criticism overwhelmingly. On 8 February, the Lancet published a statement in solidarity with Chinese professionals in combating the novel coronavirus outbreak and called upon fighting against the army of infodemics ${ }^{23,24}$. Later, more and more public health scientists have endorsed this statement.

\section{Collective perceptual bias to COVID-19 in scientific community}

Given that multifarious stigmatized monikers have become dominant in the public, what's about in scientific sphere? It is critical that having individuals who are well versed in naming conventions for new viruses and pathogenic diseases and collaborate directly with 
researchers on a regular basis. Unfortunately, before the antidotes to infodemic - proper names - find their ways into the public mind, debate on interim solutions has been going on (Table 1).

On 12 January 2020, WHO provisionally named the 2019 novel coronavirus disease "2019-nCoV". China's National Health Commission (CNHC) decided to temporarily call the disease "Novel Coronavirus Pneumonia" or "NCP" on 7 February. This official name has invoked intensive arguments outside as well as inside the scientific community. Firstly, Chinese scientists are divided on that official name. Supporters say the descriptive name follows typical classification practices, whereas opponents claim that it could be easily misunderstood and abused to sow the seeds for panic. Secondly, the word 'novel' is confusing in the way that neither the disease nor the host range can be used to reliably determine the virus novelty. Arguably, high mutation and gene recombination rates make this type of virus ideal for pathogen evolution ${ }^{25}$. Once viral mutation happened, it won't be 'novel' any more.

Table 1 Chronological list of published articles with multifarious proposal names*

\begin{tabular}{|c|c|c|}
\hline \# & Date & Article \\
\hline 1 & 18 January & $\begin{array}{l}\text { Cheng VCC, Wong S-C, To KKW, Ho PL, Yuen K-Y. Preparedness and proactive infection } \\
\text { control measures against the emerging Wuhan coronavirus pneumonia in China. J Hosp Infect } \\
\text { 2020. https://doi.org/10.1016/j.jhin.2020.01.010. }\end{array}$ \\
\hline 2 & 20 January & $\begin{array}{l}\text { Parry J. China coronavirus: cases surge as official admits human to human transmission. Br Med } \\
\text { J 2020;368:m236. https://doi.org/10.1136/bmj.m236. }\end{array}$ \\
\hline 3 & 21 January & Stop the Wuhan virus. Nature $2020 ; 577: 450-450$. https://doi.org/10.1038/d41586-020-00153-x. \\
\hline 4 & 22 January & $\begin{array}{l}\text { Callaway E, Cyranoski D. China coronavirus: Six questions scientists are asking. Nature 2020; } \\
\text { 577:605-7. https://doi.org/10.1038/d41586-020-00166-6. }\end{array}$ \\
\hline 5 & 22 January & $\begin{array}{l}\text { Liu S-L, Saif L. Emerging Viruses without Borders: The Wuhan Coronavirus. Viruses 2020; } \\
\text { 12:130. https://doi.org/10.3390/v12020130. }\end{array}$ \\
\hline 6 & 23 January & $\begin{array}{l}\text { Callaway E, Cyranoski D. Why snakes probably aren't spreading the new China virus. Nature } \\
\text { 2020. https://doi.org/10.1038/d41586-020-00180-8. }\end{array}$ \\
\hline 7 & 24 January & $\begin{array}{l}\text { Mahase E. China coronavirus: what do we know so far? Br Med J 2020;368:m308. } \\
\text { https://doi.org/10.1136/bmj.m308. }\end{array}$ \\
\hline 8 & 28 January & $\begin{array}{l}\text { Mahase E. China coronavirus: mild but infectious cases may make it hard to control outbreak, } \\
\text { report warns. Br Med J 2020;368:m325. https://doi.org/10.1136/bmj.m325. }\end{array}$ \\
\hline 9 & 29 January & $\begin{array}{l}\text { Parry J. China coronavirus: partial border closures into Hong Kong are not enough, say doctors. } \\
\text { Br Med J 2020;368:m349. https://doi.org/10.1136/bmj.m349. }\end{array}$ \\
\hline 10 & 31 January & $\begin{array}{l}\text { Callaway E. China coronavirus: labs worldwide scramble to analyse live samples. Nature 2020; } \\
\text { 578:16-16. https://doi.org/10.1038/d41586-020-00262-7. }\end{array}$ \\
\hline 11 & 31 January & $\begin{array}{l}\text { Mahase E. China coronavirus: WHO declares international emergency as death toll exceeds } 200 . \\
\text { Br Med J 2020;368:m408. https://doi.org/10.1136/bmj.m408. }\end{array}$ \\
\hline 12 & 31 January & $\begin{array}{l}\text { Bassetti M, Vena A, Giacobbe DR. The novel Chinese coronavirus (2019-nCoV) infections: } \\
\text { Challenges for fighting the storm. Eur J Clin Invest 2020: e13209. } \\
\text { https://doi.org/10.1111/eci.13209. }\end{array}$ \\
\hline 13 & 31 January & $\begin{array}{l}\text { Ralph R, Lew J, Zeng T, Francis M, Xue B, Roux M, et al. 2019-nCoV (Wuhan virus), a novel } \\
\text { Coronavirus: human-to-human transmission, travel-related cases, and vaccine readiness. J Infect } \\
\text { Dev Ctries 2020; 14:3-17. https://doi.org/10.3855/jidc.12425. }\end{array}$ \\
\hline 14 & 3 February & $\begin{array}{l}\text { Wu F, Zhao S, Yu B, Chen Y-M, Wang W, Song Z-G, et al. A new coronavirus associated with } \\
\text { human respiratory disease in China. Nature 2020. https://doi.org/10.1038/s41586-020-2008-3. }\end{array}$ \\
\hline 15 & 4 February & $\begin{array}{l}\text { ry J. China coronavirus: Hong Kong health staff strike to demand border closure as city } \\
\text { ords first death. Br Med J 2020;368:m454. https://doi.org/10.1136/bmj.m } 454 \text {. }\end{array}$ \\
\hline 16 & 5 February & $\begin{array}{l}\text { Jiang S, Xia S, Ying T, Lu L. A novel coronavirus (2019-nCoV) causing pneumonia-associated } \\
\text { respiratory syndrome. Cell Mol Immunol 2020. https://doi.org/10.1038/s41423-020-0372-4. }\end{array}$ \\
\hline
\end{tabular}

$17 \quad 7$ February

Cyranoski D. Did pangolins spread the China coronavirus to people? Nature 2020. https://doi.org/10.1038/d41586-020-00364-2.

1811 February Wang L-F, Anderson DE, Mackenzie JS, Merson MH. From Hendra to Wuhan: what has been learned in responding to emerging zoonotic viruses. Lancet 2020;395: e33-4. https://doi.org/10.1016/S0140-6736(20)30350-0.

1911 February

Gorbalenya AE, Baker SC, Baric RS, Groot RJ De, Gulyaeva AA, Haagmans BL, et al. The species and its viruses - a statement of the Coronavirus Study Group. BioRxiv 2020. https://doi.org/10.1101/2020.02.07.937862.

2012 February Zhou T, Liu Q, Yang Z, Liao J, Yang K, Bai W, et al. Preliminary prediction of the basic reproduction number of the Wuhan novel coronavirus 2019-nCoV. J Evid Based Med 2020. https://doi.org/10.1111/jebm.12376.

2114 February Jiang S, Shi Z-L. The First Disease X is Caused by a Highly Transmissible Acute Respiratory Syndrome Coronavirus. Virol Sin 2020. https://doi.org/10.1007/s12250-020-00206-5.

2219 February

Jiang S, Shi Z, Shu Y, Song J, Gao GF, Tan W, et al. A distinct name is needed for the new coronavirus. Lancet 2020. https://doi.org/10.1016/S0140-6736(20)30419-0.

2319 February $\quad$ G. K.-M. Goh, A. K. Dunker, J. A. Foster, V. N. Uversky, Rigidity of the Outer Shell Predicted by a Protein Intrinsic Disorder Model Sheds Light on the COVID-19 (Wuhan-2019-nCoV) Infectivity. Biomolecules. 10, 331 (2020).

2419 February $\quad$ S. Kooraki, M. Hosseiny, L. Myers, A. Gholamrezanezhad, Coronavirus (COVID-19) Outbreak: What the Department of Radiology Should Know. J. Am. Coll. Radiol. (2020), doi:10.1016/j.jacr.2020.02.008.

2526 February J. Xia, J. Tong, M. Liu, Y. Shen, D. Guo, Evaluation of Coronavirus in Tears and Conjunctival Secretions of Patients With SARS-CoV-2 Infection. J. Med. Virol. (2020), doi:10.1002/jmv.25725.

Proposal Name

Wuhan Coronavirus

Pneumonia

China Coronavirus

Wuhan Virus

China Coronavirus

Wuhan Coronavirus

China Virus

China Coronavirus

China Coronavirus

China Coronavirus

China Coronavirus

China Coronavirus

Novel Chinese Coronavirus

Wuhan Virus

WH-Human-1 Coronavirus

(Wuhan-Human-1

Coronavirus)

China Coronavirus

PARS-CoV (Pneumonia Acute Respiratory Syndrome Coronavirus)

China Coronavirus

HARS-CoV (Han Acute

Respiratory Syndrome Coronavirus)

SARS-CoV-2 (Severe Acute Respiratory Syndrome coronavirus 2)

Wuhan Novel Coronavirus

TARS-CoV (Transmissible Acute Respiratory Syndrome Coronavirus)

HCoV-19 (Human

Coronavirus 2019)

Wuhan-2019-nCoV

NCIP (Novel coronavirus-

infected pneumonia)

NCP (Novel Coronavirus

Pneumonia)

*Note: As of 26 February 2020, the articles have been retrieved from the PubMed. 
Before that, the 2019 novel coronavirus was designated as "WH-Human-1 coronavirus" or "Wuhan-Human-1 coronavirus" by a group of scientists in Nature on 3 February ${ }^{26}$. In the same vein, on 11 February, another name "HARS-CoV”, with 'Han' standing for 'Wuhan in Chinese', was proposed in The Lancet ${ }^{27}$. Obviously, such practices are against the naming principles of $\mathrm{WHO}^{28}$ - geographic locations should be avoided in disease names, and the name should be short and easy to pronounce. Such names might provoke unintended negative impacts by stigmatizing Wuhan citizens and even Chinese people. Those flawed notions take hold should be duly corrected, as well as other similar paradigms (Table 1).

In response to such concerns, on 11 February, WHO officially renamed "2019-nCoV” as "COVID-19", with 'CO' meaning 'corona', 'VI' for 'virus', 'D' for 'disease', and '19' referring to 2019. This generic descriptive reassignment offers an overdue corrective to those strongly-held but flawed notions, with the hope of minimizing stigma. Coinciding with the WHO's latest announcement, in a bioRxiv preprint $^{29}$, a new name "Severe Acute Respiratory Syndrome coronavirus 2" or "SARS-CoV-2" was penned by the Coronavirus Study Group of the International Committee on Taxonomy of Viruses (ICTV-CSG) on the same day. ICTV-CSG explains that this designation highlights the new strain's similarity to the SARS-CoV ${ }^{10}$. It is unclear whether the ICTV will take this suggestion into consideration.

In the real dilemma, WHO and some prominent virologists are far less skewed towards SARS-CoV-2, the nomenclature endorsed by ICTV-CSG ${ }^{30,31}$. Outside the academic-industrial sphere, people also argued against this official name. Although "SARS-CoV-2" seems to be natural for ICTV-CSG to add a numeral '2' behind "SARS-CoV" to signify their relation, many prominent scientists scramble to refute the latest claim. To the untrained eye, the hasty designation may mislead the public to perceive a severer strain virus as a direct descendant of SARS-CoV in plain sight, rather than a close affinity for the causative agent of China's another major viral outbreak in 2002-03. Before that, on 5 February, Prof. Shibo Jiang and his colleagues proposed another name, "Pneumonia Acute Respiratory Syndrome Coronavirus" or "PARS-CoV" in Cellular \& Molecular Immunology ${ }^{32}$. In the same token, this assignment also intends to retain equivalent terminology of SARS-CoV. Nonetheless, only two weeks later, without mention of their earlier similar formulations ${ }^{32,33}$, they reintroduced the third name "HCoV-19" ("Human coronavirus 2019") in the Lancet t1 $^{31}$ objecting to the usage of SARS-CoV-2.

In fact, the looming worry is that the public are susceptible to SARS-CoV ${ }^{16}$, which evokes the memory of higher case fatality ratio. On 9 February, Chen Huan-chun, Chinese academician and virologist, made a public apology for mistakenly saying 2019-nCoV is SARS$\mathrm{CoV}$, which had stung a sensitive nerve and aroused great consternation in the Chinese public.

Layered on top of mediate infodemic risks, making informed and judicious choice is a catch-22 for each authoritative body. It is necessary to punctuate heuristic cautions and continuous introspection of previous multifarious names ${ }^{14,16,28,30}$, which is a requisite bedrock of such scientific efforts. Recently, global profusion of squab candidates has been discussed inside the scientific community, as well as on social media. For example, TARS- $\mathrm{CoV}^{33}$ and $\mathrm{CARS}-\mathrm{CoV}$, with 'ARS' standing for 'acute respiratory syndrome', 'T' for 'transmissible', and 'C' for 'contagious'. Whatever merits and demerits, some of them with plausible reasons should be fairly recognized. Before the pull of academic accession, authority should take an open mind to appreciate modest introspections and rededications to such collective efforts. On 22 February, CNHC officially renamed the temporary English name "NCP" as "COVID-19", with the hope of sitting well with the reference of WHO and further discouraging the use of stigmatized titles ${ }^{34}$.

\section{Discussion}

With an emphasis on infodemiological analysis and meta-analysis on COVID-19 epidemic and COVID-19 infodemic, we scrutinize collective communication behaviors on the Internet and pertinent usages in publications in sociocultural paradigms to uncover some unfolded motivations and consequences:

[1] As an earlier nomenclature practice, the neologism "coronavirus" came from the idea of Anthony Peter Waterson and his colleagues. Due to the misjudgments of its debut in textbooks, the history of science and technology might be redefined, which might result in discouraging us to reminisce those unsung pioneers who have inaugurated induction and stimulation of seminal inspiration.

[2] Infodemic follows closely on the heels of every pathogen like never-departing shadow ${ }^{4}$. The portfolio of full-fledged official names would duly discourage the spread of regional stigmatization and racial discrimination, and reverse negative perceptual bias and collective behavioral propensities amid global public health crisis.

[3] People around the globe are divided in their favor stigmatized monikers because of perceptual bias in the public and scientific communities. Perceptual bias in the perception of natural origin of COVID-19 is part of the reason for negative behavioral propensities in specific regions, rather than the degree of infection in their territories.

[4] The prognostic significance of above findings is that infodemiological analysis could be expected to provide a hallmark reference to reframe extensible discussions on the approaching tipping point of psychological typhoon eye effect in the COVID-19 infodemic, as well as substantial patterns of the next infodemic.

At this critical moment, an epoch-making name is expected to be scientifically pithy and socially acceptable, with the faith of minimizing unintentional negative impacts on nations, economies and people. This is a positivist doctrine, not merely for naming a virus but for the vitality of science and the promotion of social progress. Obviously, some naming practices went awry. Learning lessons of infodemic could surely be seen as a pressing necessity of yielding up some guidelines for the adoption of practical principles intended to enhance the possibility for the lessening of stigmatization and discrimination.

Technically, we now see collaborative efforts as a potential way to help strengthen and standardize ongoing international initiatives of WHO and ICTV. Admittedly, understanding of the way naming rules strengthen and enrich the integrity and quality of naming practices under the umbrella of original mission remains nominal rather than substantial ${ }^{14,16,28,30}$. For example, as the precaution, the word 'novel' was recommended by WHO for "indicating a new pathogen of a previously known type, recognizing that this term will become obsolete if other new pathogens of that type are identified." 15 However, stakeholders frequently reserve 'novel' for striking new type of virus, lest the word lose fundamentally its impact without regular amendments.

\section{Methods}

As of 29 February 2020, COVID-19 has spread to 60 countries and territories. Of these, the World Health Organization (WHO) published the number of cumulative cases in 54 Member States on 29 February 2020, as well as Hong Kong, Macao and Taiwan (https://www.who.int/emergencies/diseases/novel-coronavirus-2019/situation-reports). We retrieved from the cumulative cases of three 
non-member states - Iceland, Azerbaijan and Monaco - from their official websites. The corresponding total populations of 2019 comes from United Nations (Department of Economic and Social Affairs, Population Division (2019). World Population Prospects 2019. Rev. 1.).

Moreover, metadata from three information sources, electronic books corpus (Google Books Ngram Corpus (GBNC)), journals (Web of Science (WoS) and PubMed) and the Internet (Google Trends Index (GTI)), will be retrieved and orchestrated to facilitate subsequent analysis. GBNC is a unique linguistic landscape that benefits from centuries of development of rich grammatical and lexical resources as well as cultural contexts ${ }^{35}$. WoS and PubMed are learned publications databases with rich structural meta-data. GTI is knowledge dissemination metrics for query incidence of relevant keywords and phrases. The dynamic spatiotemporal patterns of GTI are faith mirrors of demographic perceptions and collective behavioral propensities.

Infodemiology is a science portfolio of information science and epidemiology to address the pressing concerns for public health and policy decisions ${ }^{36,37}$. Under the umbrella of infodemiological scenarios, meta-analysis on diachronic discourses of pertinent keywords and phrases promises to articulate the unfolding chronological picture since their debutants on a historical time scale ${ }^{38}$. For examples, the earliest usage track-down of "coronavirus" and "coronaviruses" could provide an insightful and compelling argument for rigorous historical story, and finally help us penetrate to the essence of reality. Diachronic discourse of "coronavirus", "coronaviruses", "Coronaviridae" and "Nidovirales" in English corpus could reflect the historical milestones and the status quo in the field of human coronaviruses research. In current COVID infodemic, stigmatized monikers are ideal indicators of negative bias, and GTI is employed to determine their populational consumptions across various regions over time to characterize collective perceptual bias.

\section{References}

1. Heymann, D. L. \& Shindo, N. COVID-19: what is next for public health? Lancet 395, 542-545 (2020).

2. WHO. Novel Coronavirus (2019-nCoV) Situation Report - 13. (2020).

3. Zarocostas, J. How to fight an infodemic. Lancet 395, 676 (2020).

4. Jones, D. S. History in a Crisis — Lessons for Covid-19. N. Engl. J. Med. NEJMp2004361 (2020). doi:10.1056/NEJMp2004361

5. Almeida, J. D. et al. Virology: Coronaviruses. Nature 220, 650-650 (1968).

6. Fenner, F. The nomenclature and classification of viruses the International Committee on Nomenclature of Viruses. Virology 46, 979980 (1971).

7. Fenner, F. The Classification and Nomenclature of Viruses: Summary of Results of Meetings of the International Committee on Taxonomy of Viruses in Madrid, September 1975. J. Gen. Virol. 31, $463-470$ (1976).

8. Waterson, A. P. \& Wilkinson, L. An Introduction to the History of Virology. (Cambridge University Press, 1978).

9. Tyrrell, D. A. J. A New Science: What, Why, And How? Br. Med. J. 1, 45 (1979).

10. Gorbalenya, A. E. et al. The species Severe acute respiratory syndrome-related coronavirus: classifying 2019-nCoV and naming it SARS-CoV-2. Nat. Microbiol. (2020). doi:10.1038/s41564-020-0695-z

11. de Wit, E., van Doremalen, N., Falzarano, D. \& Munster, V. J. SARS and MERS: recent insights into emerging coronaviruses. Nat. Rev. Microbiol. 14, 523-534 (2016).

12. Cui, J., Li, F. \& Shi, Z.-L. Origin and evolution of pathogenic coronaviruses. Nat. Rev. Microbiol. 17, 181-192 (2019).

13. Chinazzi, M. et al. The effect of travel restrictions on the spread of the 2019 novel coronavirus (COVID-19) outbreak. Science eaba9757 (2020). doi:10.1126/science.aba9757

14. Enserink, M. Amid heightened concerns, new name for novel coronavirus emerges. Science 340, 673 (2013).

15. WHO. World Health Organization Best Practices for the Naming of New Human Infectious Diseases. 1-3 (2015).

16. Enserink, M. War Stories. Science 339, 1264-1268 (2013).

17. Rothkopf, D. J. When the Buzz Bites Back. The Washington Post, B1 (2003).

18. Davis, J. T., Perra, N., Zhang, Q., Moreno, Y. \& Vespignani, A. Phase transitions in information spreading on structured populations. Nat. Phys. (2020). doi:10.1038/s41567-020-0810-3

19. The Lancet. COVID-19: too little, too late? Lancet 395, 755 (2020).

20. Cowper, A. Covid-19: are we getting the communications right? Br. Med. J. m919 (2020). doi:10.1136/bmj.m919

21. Kupferschmidt, K. \& Cohen, J. Can China's COVID-19 strategy work elsewhere? Science 367, 1061-1062 (2020).

22. Silver, L., Devlin, K. \& Huang, C. China's Economic Growth Mostly Welcomed in Emerging Markets, but Neighbors Wary of Its Influence. (2019).

23. Calisher, C. et al. Statement in support of the scientists, public health professionals, and medical professionals of China combatting COVID-19. Lancet (2020). doi:10.1016/S0140-6736(20)30418-9

24. COVID-19: fighting panic with information. Lancet 395, 537 (2020).

25. Morens, D. M., Daszak, P. \& Taubenberger, J. K. Escaping Pandora's Box - Another Novel Coronavirus. N. Engl. J. Med. NEJMp2002106 (2020). doi:10.1056/NEJMp2002106

26. Wu, F. et al. A new coronavirus associated with human respiratory disease in China. Nature (2020). doi:10.1038/s41586-020-2008-3

27. Wang, L.-F., Anderson, D. E., Mackenzie, J. S. \& Merson, M. H. From Hendra to Wuhan: what has been learned in responding to emerging zoonotic viruses. Lancet 395, e33-e34 (2020).

28. Fukuda, K., Wang, R. \& Vallat, B. Naming diseases: First do no harm. Science 348, 643-643 (2015).

29. Gorbalenya, A. E. et al. The species and its viruses - a statement of the Coronavirus Study Group. bioRxiv (2020). doi:10.1101/2020.02.07.937862

30. Enserink, M. Update: 'A bit chaotic.' Christening of new coronavirus and its disease name create confusion. Science (2020). doi:10.1126/science.abb2806

31. Jiang, S. et al. A distinct name is needed for the new coronavirus. Lancet (2020). doi:10.1016/S0140-6736(20)30419-0

32. Jiang, S., Xia, S., Ying, T. \& Lu, L. A novel coronavirus (2019-nCoV) causing pneumonia-associated respiratory syndrome. Cell. Mol. Immunol. (2020). doi:10.1038/s41423-020-0372-4

33. Jiang, S. \& Shi, Z.-L. The First Disease X is Caused by a Highly Transmissible Acute Respiratory Syndrome Coronavirus. Virol. Sin. (2020). doi:10.1007/s12250-020-00206-5

34. Zhihao, Z. China adopts COVID-19 as official English name for disease. China Daily (2020). Available at: https://www.chinadaily.com.cn/a/202002/22/WS5e506f18a31012821727970f.html. (Accessed: 22nd February 2020) 
35. Michel, J.-B. et al. Quantitative Analysis of Culture Using Millions of Digitized Books. Science 331, 176-182 (2011).

36. Eysenbach, G. Infodemiology and Infoveillance: Framework for an Emerging Set of Public Health Informatics Methods to Analyze Search, Communication and Publication Behavior on the Internet. J. Med. Internet Res. 11, e11 (2009).

37. Horvitz, E. \& Mulligan, D. Data, privacy, and the greater good. Science 349, 253-255 (2015).

38. Gurevitch, J., Koricheva, J., Nakagawa, S. \& Stewart, G. Meta-analysis and the science of research synthesis. Nature 555, 175-182 (2018). 